\title{
Functional consequences of mutations in the MODY4 gene (IPF1) and coexistence with MODY3 mutations
}

\author{
J. Weng $^{1 *}$, W.M.Macfarlane ${ }^{2 *}$, M. Lehto ${ }^{1}$, H.F. Gu ${ }^{1}$, L.M.Shepherd ${ }^{2}$, S. A. Ivarsson ${ }^{3}$, L. Wibell ${ }^{4}$, T. Smith ${ }^{5}$, \\ L. C. Groop ${ }^{1}$ \\ ${ }^{1}$ Department of Endocrinology, Malmö University Hospital, Lund University, Malmö, Sweden \\ ${ }^{2}$ School of Biochemistry \& Genetics, University of Newcastle-upon-Tyne, Newcastle-upon Tyne, United Kingdom \\ ${ }^{3}$ Department of Pediatrics, Malmö University Hospital, Lund University, Malmö, Sweden \\ ${ }^{4}$ Department of Internal Medicine, University Hospital, Uppsala, Sweden \\ ${ }^{5}$ Department of Pediatrics, Simrishamn Hospital, Simrishamn, Sweden
}

\section{Abstract}

Aims/hypothesis. The aim of this study was to examine the putative role of mutations in the insulin promoter 1 (IPF1) gene in early-onset diabetes.

Methods. We carried out mutation screening of the IPF1 gene in 115 Scandinavian families with at least two members with onset of diabetes younger than 40 years. The allele frequencies were also tested in 183 unrelated patients with late-onset Type II (noninsulin-dependent) diabetes mellitus and in 92 nondiabetic control subjects.

Results. Two novel IPF1 variants (G212R and P239Q) and one previously reported (D76N) IPF1 variant were identified in the 115 families $(3.5 \%)$. The D76N variant was found in one MODY3 family (S315fsinsA of $H N F 1 \alpha$ ) and also in two families with late-onset Type II diabetes. The P239Q variant was identified in two families with early-onset diabetes including one with MODY3 (R272C of $H N F 1 \alpha$ ) and in three families with late-onset Type II diabetes. De- spite the fact that the variants did not segregate completely with diabetes, the non-diabetic carriers of the IPF1 variants had increased blood glucose concentrations $(p<0.05)$ and reduced insulin:glucose ratios $(p<0.05)$ during an oral glucose tolerance test compared with non-diabetic family members without these variants. In addition, when the G212R and P239Q variants were expressed in cells without IPF1 i. e. . Nes 2 y cells, both variants showed about a $50 \%$ reduction in their ability to activate insulin gene transcription compared to wild-type IPF1, as measured by reporter gene assay.

Conclusion/interpretation. Although mutations in the $I P F-1$ gene are rare in early- $(3.5 \%)$ and late-onset $(2.7 \%)$ Type II diabetes, they are functionally important and occur also in families with other MODY mutations. [Diabetologia (2001) 44: 249-258]

Keywords Insulin promoter factor 1, Type II diabetes, maturity-onset diabetes of the young (MODY), gene expression, insulin gene.
Received: 15 June 2000 and in revised form: 5 October 2000

Corresponding author: Prof. L. C. Groop, Department of Endocrinology, Malmö University Hospital, S-205 02, Malmö, Sweden

Abbreviations: EMSA, Electrophoretic mobility shift assay; MODY, Maturity onset diabetes of the young; RPMI, Roswell Park Memorial Institute; IPF1, insulin promoter factor 1; SSOs, Sequence-specific oligonucleotide probes; SSCP, single strand conformation polymorphism; RFLP, restriction fragment length polymorphism.

* These two authors contributed equally to this paper
Type II (non-insulin-dependent) diabetes mellitus is a common disorder affecting more than 100 million people throughout the world. In most cases it shows a strong genetic component, particularly in families with an earlier onset of the disease. Apart from the successful identification of the underlying genetic defects in the relatively rare monogenic forms of maturity-onset diabetes in the young (MODY) little success has been made so far in the dissection of the genetic causes of the presumably polygenic forms of late-onset Type II diabetes. To date five genes have been associated with MODY, i.e. hepatocyte nuclear factor (HNF $4 \alpha$ (MODY1), glucokinase (GCK) (MODY2), the $H N F-1 \alpha$ gene (MODY3), insulin pro- 
Table 1. PCR conditions and sequences of primers for the amplification, sequencing and SSOs

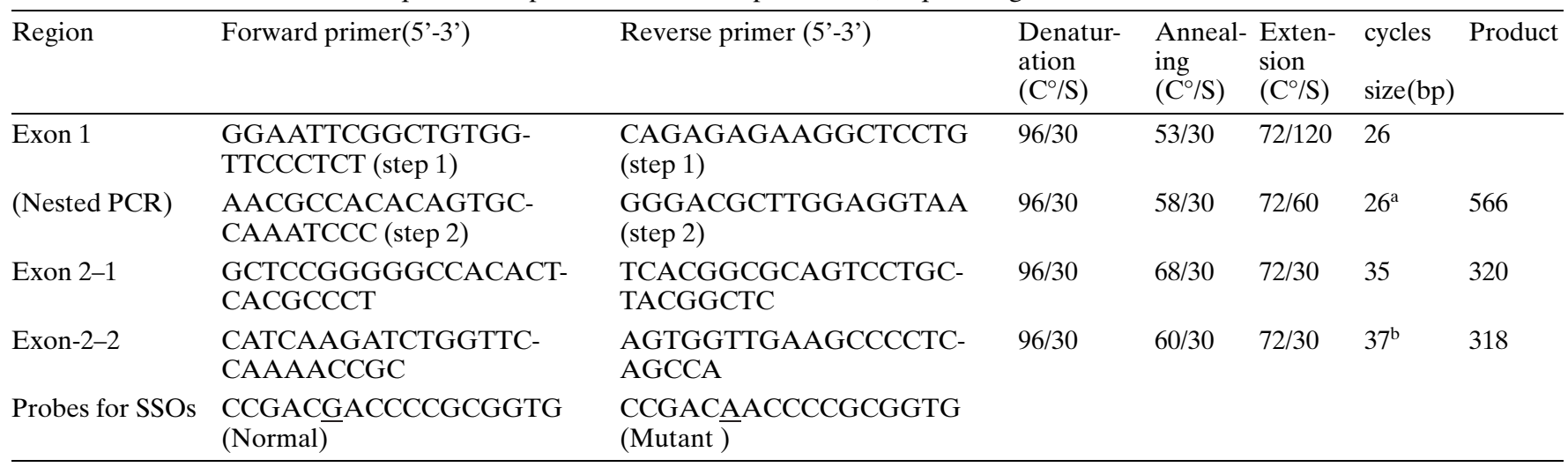

a,${ }^{\mathrm{b}} 4 \%$ formamid and $5 \%$ DMSO was used in the PCR reaction, respectively. Substituted base in the probe is underlined

moter factor 1 (IPF1) (MODY4) and $H N F-1 \beta$ (MODY5) [1, 2].

Early-onset Type II diabetes, with age at onset younger than 40 years represents a heterogeneous group including both MODY and mis-classified Type II (insulin-dependent) diabetes mellitus. In a previous study of 115 Scandinavian families with early-onset diabetes, we identified mutations in the $H N F-4 \alpha$, $G C K, H N F-1 \alpha$ and mitochondrial tRNA ${ }^{\text {Leu (UUR) }}$ genes in 15 out of the 115 families studied (13\%) [3]. In 4 of the families we also identified a novel variant in the $H N F-1 \beta$ gene [4]. In the remaining 96 families, however, we did not find any MODY1-3 and MODY5 gene mutations.

The IPF1 (also named STF1, IDX1, and PDX1) is a transcription factor that regulates early pancreatic development and mediates expression of insulin and other beta-cell-specific genes [5, 6, 7]. A single nucleotide deletion at codon 63 (Pro63fsdelC) of the IPF1 gene was described in an extended family in which a homozygous mutation carrier had pancreatic agenesis whereas the heterozygous carriers developed early-onset diabetes [8]. Missense mutations in the IPF1 gene have also been shown to be predisposed to Type II diabetes $[9,10]$.

To test whether genetic variants in the IPF1 contribute to the pathogenesis of early-onset Type II diabetes, we screened the coding regions and the flanking introns of the IPFI gene in the same cohort of 115 families with early-onset Type II diabetes. We also report three amino acid substitutions of the IPF1 gene and analysis of their functional consequences.

\section{Subjects and methods}

Subjects. Mutation screening of the human IPF1 gene was carried out in 115 Scandinavian families with early-onset diabetes. On average, the pedigrees included 9 subjects with 4 diabetic patients. Of them, there were 3 families with 1 patient, 41 fam- ilies with 2 patients, 71 families with 3 or more patients diagnosed with diabetes at age 40 or younger [3]. One diabetic patient from each family was chosen for single strand conformation polymorphism (SSCP) analysis of the IPF1 gene. The prevalence rate of the IPF1 sequence variants was also tested in 183 unrelated late-onset diabetic subjects and in 92 non-diabetic control subjects without a family history of diabetes from the Botnia study [11]. The patients with early-onset diabetes had a mean age at diagnosis of $25 \pm 10$ years, duration of diabetes of $20 \pm 13$ years, BMI of $26.5 \pm 5.5 \mathrm{~kg} / \mathrm{m}^{2}$ and fasting plasma glucose of $9.6 \pm 3.9 \mathrm{mmol} / \mathrm{l}$ [3]. Among the 115 families with early-onset diabetes, two MODY1, four MODY2, six MODY3, and three mutations in mitochondrial DNA has been previously reported. In addition, a novel $H N F-1 \beta$ variant has been found in four families. The late-onset Type II diabetic patients had an age at onset of diabetes of $50 \pm 5$ years, BMI of $28.7 \pm 4.5 \mathrm{~kg} / \mathrm{m}^{2}$ and fasting blood glucose of $9.9 \pm 4.4 \mathrm{mmol} / \mathrm{l}$. The protocols were approved by the local ethics committees and all subjects gave their informed consent to participate.

Mutation screening. Mutation screening of the IPF1 gene was carried out with radioactive-SSCP analysis. The exon 1 was amplified with nested PCR and the products were digested with BsiWI before the SSCP analysis. The exon 2 was amplified with two pairs of primers resulting in overlapping PCR fragments. Primer sequences and the PCR conditions for each specific fragment are shown (Table 1). Initial denaturation at $96^{\circ} \mathrm{C}$ for $5 \mathrm{~min}$ and final extension at $72^{\circ} \mathrm{C}$ for $10 \mathrm{~min}$ were used in all PCR applications. Samples having mobility shift in the SSCP-analysis were re-amplified with PCR without radioactivity, whereafter products were purified and sequenced on an ABI377 sequencer according to the manufacturer's instructions (Applied Biosystems, Foster City, Calif., USA).

Detection of the IPF1 gene variants. Sequence-specific oligonucleotide (SSO) technique was used to detect the variant Asp76Asn (GAC-AAC, D76N) in the late-onset Type II diabetes and control subjects. The PCR products were dotted onto positively charged nylon membranes (HybondTM-N +, Amersham, UK) and hybridized with SSOs at $55^{\circ} \mathrm{C}$ (in $50 \mathrm{mmol} / 1$ Tris-Base, $2 \mathrm{mmol} / 1$ EDTA, $0.1 \%$ SDS, $3 \mathrm{~mol} / \mathrm{l}$ tetramethylammonium chloride, $5 \cdot$ Denhardt's, and $0.1 \mathrm{mg} / \mathrm{ml}$ herring sperm DNA) (Table 1). The SSOs were labelled with digoxigenin (DIG Oligonucleotide 3'-End Labeling Kit, Boehringer Mannheim, Germany), and the bound probes were detected with alkaline phosphatase conjugated antidigoxigenin and chemiluminescent substrate CSPD (DIG Luminescent 
Detect Kit, Boehringer Mannheim, Germany). The PCRRFLP technique was used to test the prevalence of the G212R (BsmFI) and the P239Q (PstI) variants.

Analytical methods. Blood glucose during the OGTT was measured by a hexokinase method (Boehringer Mannheim, Mannheim, Germany). Haemoglobin $\mathrm{A}_{1 \mathrm{c}}$ was measured by highpressure liquid chromatography with a normal range of 4.0 to $6.0 \%$ (Diamat Analyzer, Biorad Laboratories, Germany). Serum insulin concentrations were measured by a double-antibody radioimmunoassay (Pharmacia, Uppsala, Sweden) with an interassay coefficient of variation of $7 \%$. Serum total cholesterol, HDL subfractions (after precipitation) and triglyceride concentrations were measured on a Cobas Mira analyzer (Hoffman LaRoche, Basel, Switzerland).

Mutagenesis and Expression of IPF1 Mutants. Mutagenesis of the IPF-1 gene was done using the Altered Sites II Mammalian Mutagenesis System (Promega, U.K.) and was carried out according to the manufacturer's protocols. Two 18-mer oligonucleotides (Cruachem, U.K.) containing single base mutations were utilised to introduce the G212R and P239Q mutations. Each mutant oligonucleotide was used in conjunction with the Ampicillin repair oligonucleotide provided with the vector (Promega). Mutagenesis was confirmed by standard dideoxy sequencing of both strands of the mutant plasmids (USB, USA). Mutant proteins were expressed in Nes 2 y cells directly from the pALTER vector, which uses a eukaryotic CMV promoter. Plasmid DNA was prepared using the Qiagen Endotoxin-Free Maxiprep Kit, (Qiagen, U.K.) according to the manufacturer's protocols. Transfections were done using a minimum of two separate plasmid preparations and DNA was analysed spectrophotometrically for purity and quantification.

Transfections. The Nes2y cells were grown and transfected as described previously [12]. To investigate the ability of the mutant IPF1 proteins, to activate transcription of the insulin gene, cells expressing normal IPF1, G121R or P239Q were transfected with pGL-Luc200, a reporter gene construct containing the -60 to -260 region of the human insulin gene promoter (LUC200) or a control construct, pGL-Luc, lacking the -60 to -260 region. Treatment of transfected cells started with a $5 \mathrm{~h}$ preincubation in RPMI containing $3 \mathrm{mmol} / \mathrm{l}$ glucose. Where appropriate, cells were stimulated for $30 \mathrm{~min}$ (cell extracts) or $3 \mathrm{~h}$ (reporter gene assays) with $20 \mathrm{mmol} / \mathrm{l}$ glucose. Cells were then removed from the wells and a cell pellet recovered by centrifugation at $7000 \mathrm{rpm}$ for $30 \mathrm{~s}$. The cell pellet was resuspended in $70 \mu \mathrm{l}$ of $100 \mathrm{mmol} / 1 \mathrm{KH}_{2} \mathrm{PO}_{4} \mathrm{pH} 7.8 / 1 \mathrm{mmol} / 1$ DTT solution and lysed by freeze/thawing three times. Cell debris was removed by centrifugation at $13000 \mathrm{rpm}$ for $1 \mathrm{~min}$. Nuclear extract preparation, luciferase assays and protein quantitations were carried out as described previously [12]. Transient CAT reporter gene assays were done using the Quant-T-CAT Assay System (Amersham, U.K.) according to the manufacturer's protocols. Samples were equalised for protein concentrations.

Plasmids. The reporter gene constructs pGL-LUC and pGLLUC200 were as described previously [12]. Construct pCAT5xB contains five copies of oligonucleotide B (containing the $\mathrm{A} 3$ site of the human insulin gene promoter) upstream of the chloramphenicol acetyl transferase (CAT) reporter gene [13]. The Gal4 fusion constructs [14] were as follows: pGAL-CAT contains five copies of the Gal4 DNA binding site cloned upstream of the CAT reporter gene, pGal-empty is an expression plasmid containing the GAL4 DNA binding domain, and plasmids pGAL-IPF1, pGAL-G212R and
pGALP239Q are derived from this vector, with IPF1, G212R or P239Q cDNAs cloned immediately downstream of the Gal4 sequence, respectively.

Western Blotting. Western blot analysis was carried out using a specific IPF1 antibody (a kind gift from Dr C. V. Wright, Vanderbilt University, USA). Nuclear extracts were prepared as described previously [9]. Samples were equalised for protein concentration. The $1 \mu \mathrm{g}$ samples of cell extract were fractionated by SDS-PAGE and blotted on to ECL-nitrocellulose membrane (Amersham) and incubated for $60 \mathrm{~min}$ in a buffer containing $10 \mathrm{mmol} / \mathrm{l}$ Tris-HCl, $0.05 \%$ (v/v) Tween 20, $0.5 \mathrm{~mol} / \mathrm{l}$ $\mathrm{NaCl}$, and a 1:5000 dilution of anti-IPF1 antibody. The antigen-antibody complex was then detected by incubating the membrane for a further $60 \mathrm{~min}$ in buffer containing a 1:5000 dilution of horseradish-peroxidase conjugated anti-rabbit $\mathrm{IgG}$ secondary antibody.

Electrophoretic mobility shift assay (EMSA). Analysis of binding activity was done by electrophoretic mobility shift assay (EMSA), using the A3 site of the human insulin gene promoter as described previously $[9,12]$. Nuclear extracts were prepared from untransfected Nes2y cells and from Nes2y cells over-expressing IPF1, G212R or P239Q. Samples were equalised for protein concentration. These extracts ( $0.5 \mathrm{~g}$ of protein) were then incubated with radiolabelled probe for $20 \mathrm{~min}$ at room temperature in buffer containing $10 \mathrm{mmol} / \mathrm{l}$ Tris- $\mathrm{HCl} \mathrm{pH} 7.5$, $50 \mathrm{mmol} / 1 \mathrm{KCl}, 5 \mathrm{mmol} / \mathrm{l}$ dithiothreitol, $1 \mathrm{mmol} / 1$ EDTA, and $5 \%$ ( $\mathrm{vol} / \mathrm{vol}$ ) glycerol. To confirm equal loading of the samples, the same nuclear extracts were analysed for the binding activity of a second transcription factor USF (upstream stimulatory factor), which binds to an adjacent site within the human insulin gene promoter [9]. The USF binding activity was comparable in all five samples (data not shown).

Statistical analysis. The results are presented as means \pm SEM. Significance of differences between group means was tested by the Mann-Whitney U test. A $p$ value less than 0.05 was considered as statistically significant.

\section{Results}

Mutation screening. We screened 115 Scandinavian families with early-onset Type II diabetes (onset $<40$ years) for variants in the IPFI gene using SSCP and direct sequencing and found three sequence variants (Table 2). To obtain estimates of allele frequencies in the patients with late-onset Type II diabetes and healthy control subjects, we also screened 183 patients with Type II diabetes and 92 healthy control subjects without family history of diabetes.

A missense mutation $\mathrm{D} 76 \mathrm{~N}(\mathrm{GAC} \rightarrow \mathrm{AAC})$ was found in exon 1 of the IPF1 gene in family GS (Fig.1). The diabetic members of this family also carried an insertion mutation in the $H N F-1 \alpha$ gene (S315fsinsA, MODY3). All 14 tested diabetic patients in the family carried the S315fsinsA mutation in the $H N F-1 \alpha$ gene. The D76N variation was detected in only two out of 35 family members in the GS family (Fig. 1). The IPF1 D76N variant is most likely transmitted from the non-diabetic mother to the af- 
Table 2. Variants in the insulin promoter factor 1 (IPF1) gene in patients with early-onset Type II diabetes (age at onset $<40$ years), patients with late-onset Type II diabetes and in non-diabetic control subjects without a family history of diabetes

\begin{tabular}{llllll}
\hline Exon & Codon & Amino acid variant & \multicolumn{2}{l}{ Allele frequencies } \\
\cline { 3 - 6 } & & & $\begin{array}{l}\text { Early onset diabetes } \\
n=115(\%)\end{array}$ & $\begin{array}{l}\text { Late onset diabetes } \\
n=183(\%)\end{array}$ & $\begin{array}{l}\text { Non-diabetic control subjects } \\
n=92(\%)\end{array}$ \\
\hline 1 & 76 & Asp (GAC)-Asn (AAC) $)^{\mathrm{a}}$ & $1(0.4)$ & $2(0.5)$ & 0 \\
2 & 212 & Gly (GGG)-Arg (AGG) & $1(0.4)$ & 0 & 0 \\
2 & 239 & Pro (CCG)-Gln (CAG) & $3(0.8)$ & $1(0.5)$ \\
\hline
\end{tabular}

${ }^{a}$ Also identified in families with MODY3

fected daughter. The affected daughter (with variants in the IPFI and $H N F-1 \alpha$ genes) required insulin treatment after 7 years, whereas her cousin with only the $H N F-1 \alpha$ gene mutation required insulin after 14 years. The D76N variant was also detected in 2 of the 183 patients with late-onset Type II diabetes but in none of the control subjects. It did, however, not co-segregate with diabetes in these families; only 2 out of 11 family members carried the variant in family $\mathrm{E}$ and $\mathrm{F}$ (Fig. 1).

Two novel missense mutations were identified in exon 2 of the IPF1 gene: G212R (GGG $\rightarrow$ AGG) and P239Q (CCG $\rightarrow$ CAG). The amino acid substitution G212R, which results in loss of a BsmFI restriction site, was found in family B, in which it did not cosegregate with diabetes (Fig.1). Three out of 13 family members (6 diabetic patients) carried this mutation. There was no G212R mutation carrier in the patients with late-onset Type II diabetes or in the control group.

The third sequence variant $\mathrm{P} 239 \mathrm{Q}$, which induces a PstI restriction site, was identified in two families with early-onset diabetes (C and JS in Fig.1). Again, one of them (JS family) also had mutations in the $H N F-1 \alpha$ gene (R272C). All 4 diabetic patients in the JS family carried the R272C mutation in the $H N F$ $1 \alpha$ gene, 2 of the 4 diabetic patients also had the P239Q IPF1 mutation. The diabetic patients carrying both the IPFI and $H N F-1 \alpha$ mutations required insulin treatment after 5 and 2 years, respectively, whereas none of the MODY3 patients with mutations in only the $H N F 1 \alpha$ gene was on insulin treatment after 33 and 8 years (Fig. 1, family JS). Three carriers of the $P 239 \mathrm{Q}$ variant were found among the patients with late-onset Type II diabetes and in one of the non-diabetic control subjects (Fig. 1; A, D, G). The prevalence of the $\mathrm{P} 239 \mathrm{Q}$ variant did not differ between the patients with early-onset $(1.7 \%)$ or lateonset $(1.6 \%)$ Type II diabetes, neither did it differ from that in the control subjects $(1.1 \%)$. Only in one family, the P239Q variant co-segregated with diabetes (Fig. 1, A).

Functional analysis of IPF1 mutants. The functional activity of the missense mutations G212R and P239Q was compared with normal IPF-1 by examin- ing three critical and well established IPF1 functional characteristics: The presence of active IPF1 in the beta-cell nucleus upon glucose stimulation, binding activity to the insulin promoter, and the ability to activate insulin gene transcription. Each mutant form of IPF1 was constructed by site-directed mutagenesis and expressed in Nes 2 y cells. The Nes 2 y cells represented a proliferating human beta-cell line, which responds to glucose in the normal physiological range, and which normally lacks functional levels of the IPF1 protein [12, 13]. Over-expression of normal IPF1 in these cells has previously been shown to restore a pattern of glucose regulation of the insulin gene promoter (reporter gene analysis) and glucose regulation of endogenous insulin mRNA concentration (northern blotting) which mimics that seen in isolated human islets of Langerhans [15].

Western blot analysis of Nes 2 y cells expressing IPF1, G212R or $\mathrm{P} 239 \mathrm{Q}$ confirmed that all three proteins expressed were similar concentrations and all active (DNA-binding) forms of the IPF1 protein were present in comparable quantities in the betacell nucleus upon stimulation of the cells with high glucose concentrations (Fig. 2A, lanes 2, 3 and 4, respectively). As previously established [13], untransfected Nes2 y cells have no detectable IPF1 protein (lane 1). EMSA analysis of the respective binding activities of the two mutants showed that both bind to the A3 site of the human insulin gene promoter with equal affinity to the wild-type IPF1 protein (Fig.2B, lanes 2, 3 and 4). Densitometric analyses confirmed that no statistically significant differences occurred with G212R and P239Q binding activity in comparison to the wild-type protein (not shown). Again, no IPF1 was detectable in untransfected cells (lane 1). As in previous studies $[9,12,13]$, binding specificity was confirmed by antibody and oligonucleotide competition EMSA analysis (data not shown). Samples were equalised for protein concentration, and confirmation of equal loading was done by analysis of the binding activity of an unrelated basal transcription factor USF. The USF binding activity was comparable in all four samples [9].

To investigate the ability of the mutant IPF1 proteins to activate transcription of the insulin gene, cells expressing normal IPF1, G212R or P239Q were 

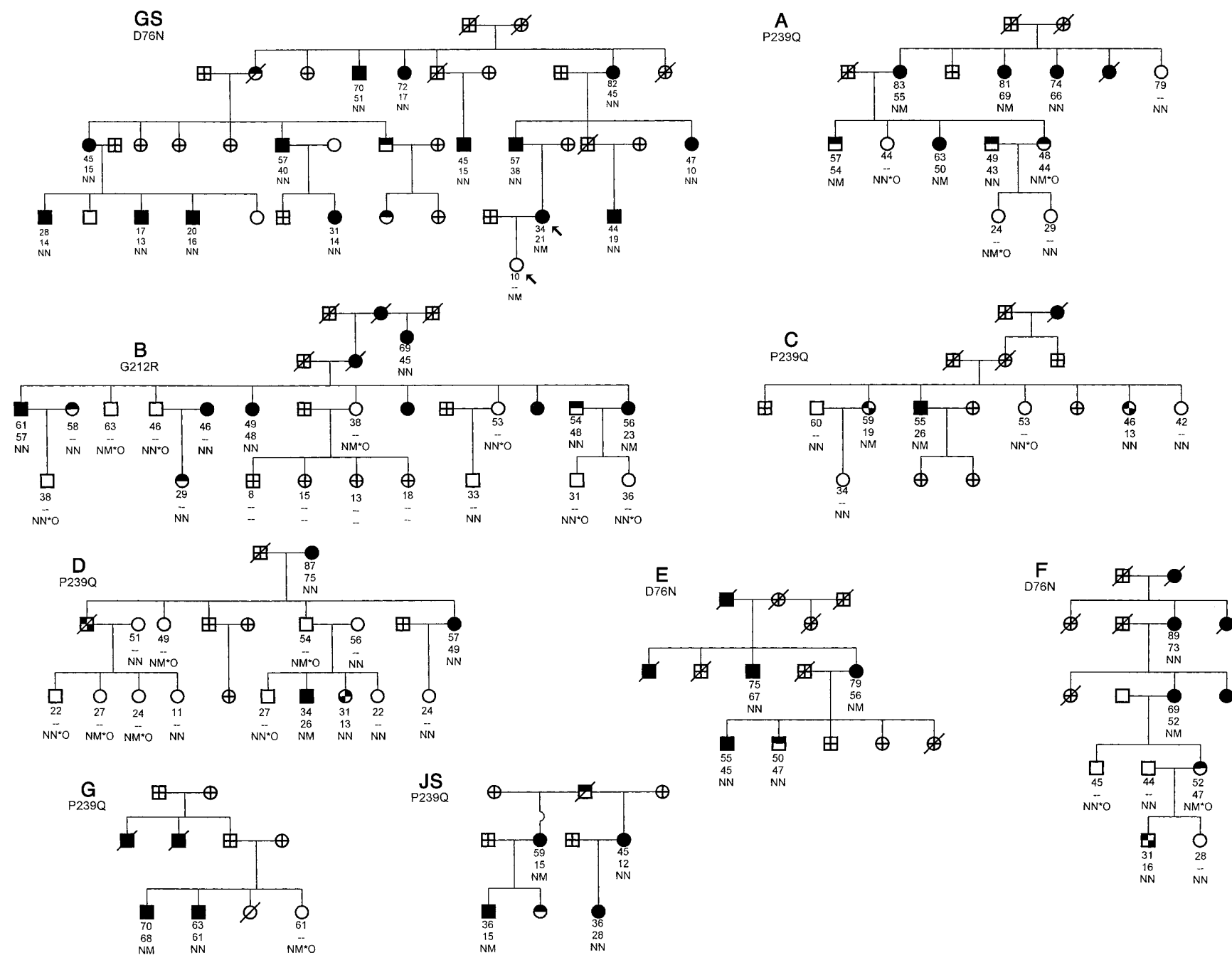

Fig. 1. Diabetic pedigrees in which variants in the IPF1 gene were detected. Family GS and JS also had the S315fsinsA and R272C mutation of HNF1 $\alpha$ gene. Filled, 2-quarter filled, upper half filled, open and crossed symbols represent subjects with Type II diabetes, Type I diabetes, impaired glucose tolerance, normal glucose tolerance and subjects who were not tested. Under each symbol, the first line indicates the present age, the second line represents age at onset of diabetes or impaired glucose tolerance and the third line shows the genotype of the IPF1 variants: $\mathrm{N}$, normal allele; $\mathrm{M}$, mutant allele; * indicates that an OGTT was done. $\square$ Type 2 diabetes; $\$$ Type 1 diatebes; $\square$ Male, healthy; $\bigcirc$ Female, healthy; $\odot$ IGT, impaired glucose tolerance; $\square$ not tested; $\varnothing$ dead

transfected with pGL-Luc200, a reporter gene construct containing the -60 to -260 region of the human insulin gene promoter (LUC200) or a control construct, pGL-Luc (LUC), lacking the -60 to -260 region (Fig. 3). When IPF1 is expressed in these cells (Fig. 3, panel B), the control construct LUC was unaffected, but the LUC200 activity increased fourfold in high glucose compared with low glucose, due to IPF1 activation of the insulin promoter. No effect of glucose was observed on either construct in the Nes 2 y cells lacking IPF1 (panel A). The expression of the two mutants G212R (panel C) and P239Q (panel D) had no effect on the control construct LUC, or on the LUC200 construct in low glucose concentrations. At high glucose concentrations, however, both showed a reduced ability to activate the insulin gene promoter compared with wild-type IPF1 (G212R 55\%: P239Q 52.5\%). As in previous studies $(9,12,13,15)$, to control for any differences in transfection efficiency, samples were equalised for protein concentration, each value represents an average of six replicates, and each result has been reproduced in three separate experiments. Error bars represent standard deviation.

Because the binding activities of the mutant proteins appeared normal, effects on transcriptional activation were confirmed firstly by analysis of the activation of a CAT reporter gene construct containing 5 copies of the A3 site of the human insulin gene promoter (pCAT5xB, Fig. 4). As observed with the insulin gene promoter constructs, both G212R (lane 3) and P239Q (lane 4) showed a reduced ability to activate reporter gene transcription in comparison to 
A

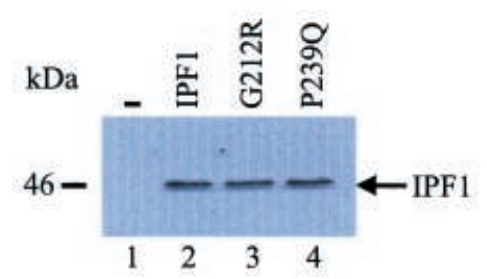

B

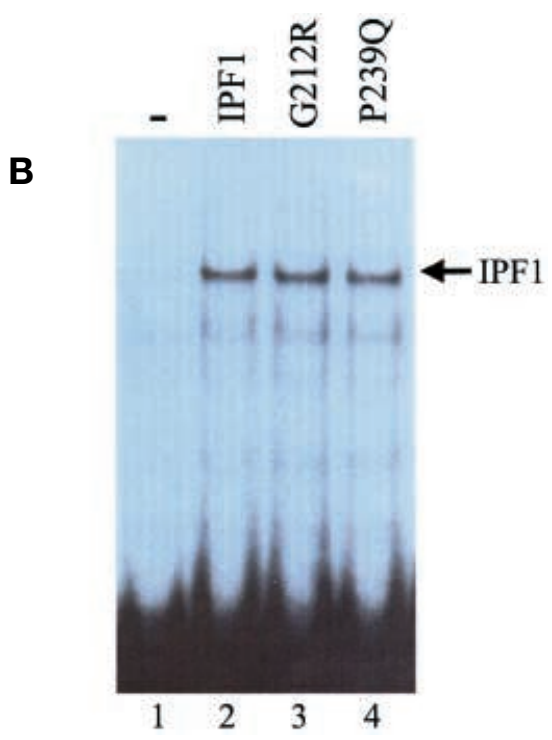

These results of the functional analyses confirm that mutations G212R and P239Q have no effect on DNA binding activity but instead have more significant effects on transcription of the insulin gene through reducing the transcriptional activation abilities of these mutant proteins than in the wild-type IPF1.

Phenotypic consequences of the variants. To study whether these variants had consequences on the phenotype, we compared clinical variables between diabetic and non-diabetic carriers of any variant (Table 3, Fig. 6) because all three tested IPF1 gene mutations seem to lead to similar defects. Subjects carrying a MODY3 mutation were excluded from the analysis (Table 3). There were no significant differences in age, age at onset of diabetes, BMI, blood pressure, $\mathrm{HbA}_{1 \mathrm{c}}$, triglyceride and fasting glucose concentrations between the diabetic subjects with the IPF1 mutation $(n=10)$ or without $(n=15)$ the IPF1 mutation. Non-diabetic carriers of the variant, however, had higher blood glucose concentrations $(p<0.05)$ and lower insulin: glucose ratios $(p<0.05)$ during the OGTT than non-diabetic family members without these variants (Fig.6). In addition, the diabetic mutation carriers had higher cholesterol concentrations than the diabetic non-carriers of the variants $\quad(6.5 \pm 0.5 \mathrm{mmol} / \mathrm{l} \quad$ vs. $\quad 5.3 \pm 0.2 \mathrm{mmol} / \mathrm{l}$; $p=0.0047)$.

\section{Discussion}

Here we identified two novel (G212R and P239Q) and one $(\mathrm{D} 76 \mathrm{~N})$ previously reported variant in the IPF1 gene in patients with early-onset and late-onset Type II diabetes. Although the variants were rare, they turned out to be functionally active and associated with impaired insulin response to the OGTT relative to the increased plasma glucose concentrations. porter gene $p G A L-C A T$ alone (lane 1). 

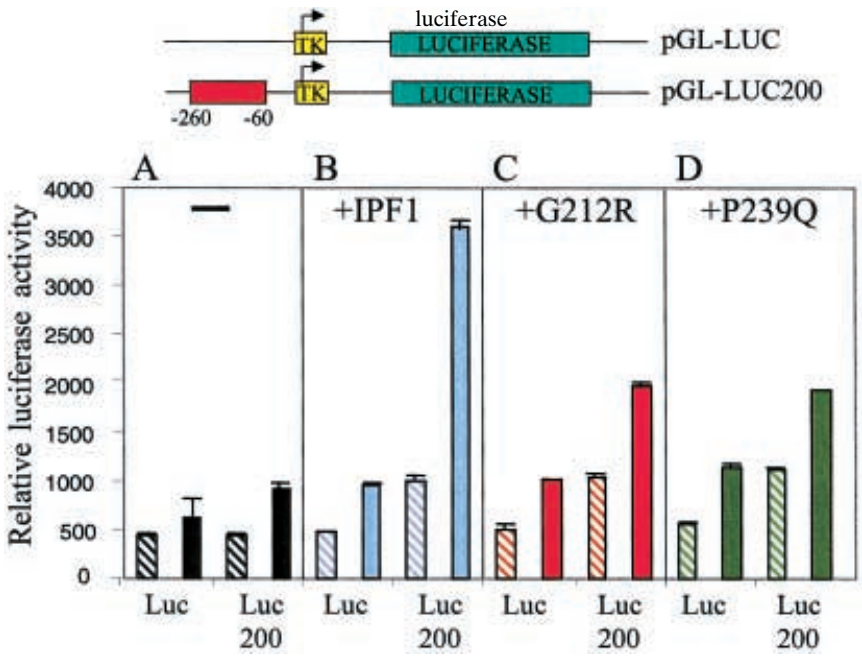

Fig.3. Analysis of the transcriptional activation of the insulin gene in Nes2y cells. Relative luciferase activity from control construct pGL-Luc (LUC), or from a construct containing the -60 to -260 region of the human insulin gene promoter pGLLuc200 (LUC200), in $3 \mathrm{mmol} / \mathrm{l}$ (hatched) or $20 \mathrm{mmol} / \mathrm{l}$ (solid) glucose. Reporter gene activity was analysed in untransfected Nes 2 y cells ( $\mathbb{N} \square$, panel A), or in Nes2 y cells expressing normal IPF1 ( ( E, panel D), respectively. Values are shown as relative luciferase activity standardised against protein content. Values represent an average from 6 replicates, error bars represent standard deviation. Each set of values has been reproduced in three separate experiments, $\mathbb{N} 3 \mathrm{mmol} / \mathrm{l}$ glucose, $20 \mathrm{mmol} / \mathrm{l}$ glucose
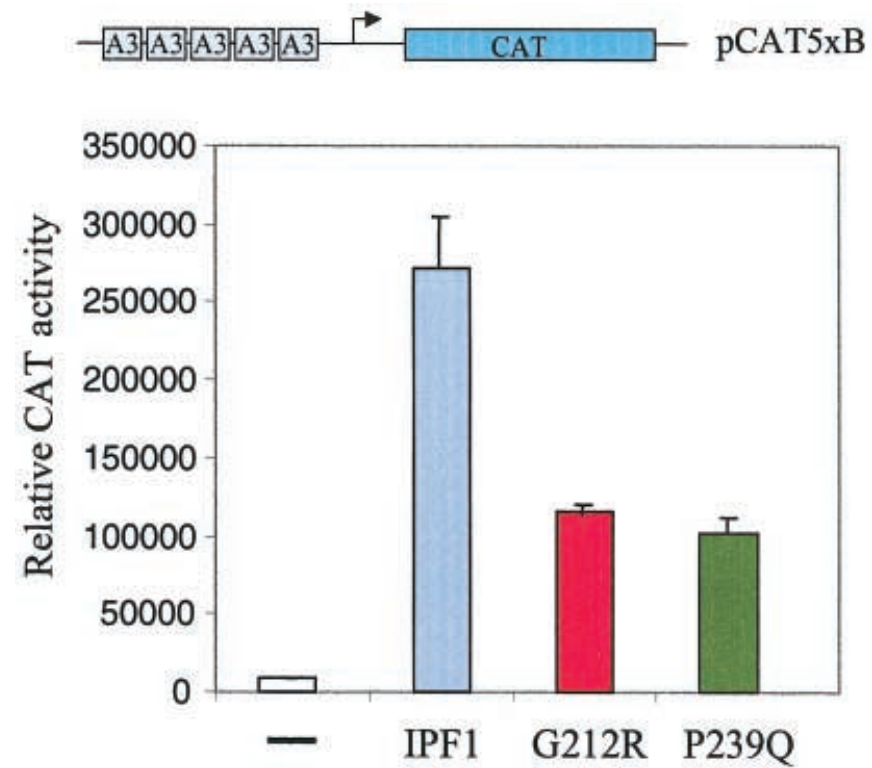

Fig.4. Relative Activation of CAT reporter gene $p C A T 5 x B$. Relative activation of the CAT reporter gene construct $p C A T 5 x B$, which contains five copies of the A3 site of the human insulin gene promoter, in Nes $2 \mathrm{y}$ cells which are untransfected ( $\square$, lane 1), or overexpressing IPF1 ( $\square$, lane 2), G212R ( $\square$, lane 3) or P239Q (国, lane 4) respectively. Values are shown as relative luciferase activity standardised against protein content. Values represent an average from 6 replicates, error bars represent standard deviation. Each set of values has been reproduced in three separate experiments
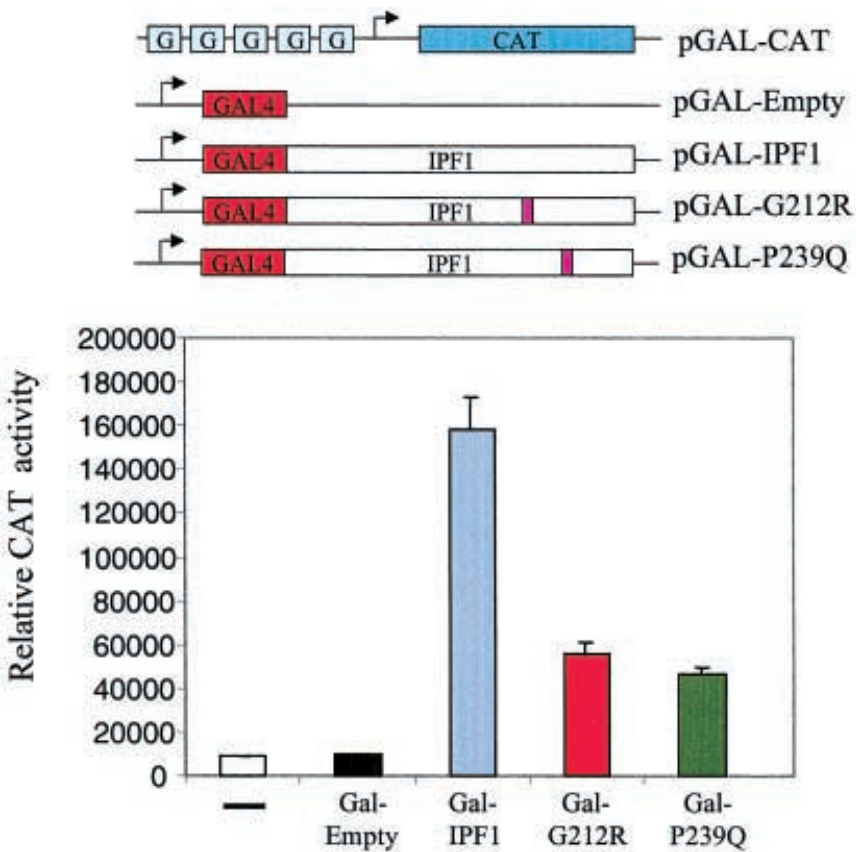

Fig. 5. Relative transcriptional activation of Gal4-IPF1 fusion proteins. Relative activation of the reporter gene construct pGAL-CAT, which contains five copies of the Gal4 DNA binding site $(\mathrm{G})$ upstream of the CAT reporter gene. Analysis was done in Nes2y cells ( $\square$, lane 1); cotransfected with the pGAL-Empty vector, expressing only the Gal4 DNA binding domain ( $\boldsymbol{\square}$, lane 2), or overexpressing the Gal4 DNA binding domain fused to IPF1 ( P239Q (国, lane 5) respectively. Values are shown as relative luciferase activity standardised against protein content. Values represent an average from 6 replicates, error bars represent standard deviation. Each set of values has been reproduced in three separate experiments

Surprisingly, two of the variants were found in families with MODY3 mutations.

The amino acids at codons 76 (Asp), 212 (Gly) and 239 (Pro) are highly conserved between the human, mouse and rat IPF1 protein sequences. The D76N mutation occurred in the amino terminal region of IPF1 that is required for transcriptional activation of the insulin gene [16]. This variant has been shown to have decreased binding activity to the A3 site of the human insulin gene promoter resulting in a $28 \%$ reduced expression of the insulin gene using a $p G L$ $L u c 200$ reporter gene [9]. The same variant was also detected in French families [10]. In this case functional studies showed that the $\mathrm{D} 76 \mathrm{~N}$ variant had a pronounced inhibitory effect on the ability of endogenous IPF1 to activate the insulin gene promoter in HIT-T15 cells compared with the wild-type IPFI. Furthermore, the French non-diabetic carriers of the D76N variant had lower insulin concentrations and insulin:glucose ratios during OGTT compared with non-diabetic subjects without the variant. In both the English and the French study the variant was associated with late-onset Type II diabetes rather than 
Table 3. Diabetic and non-diabetic subjects with ${ }^{\mathrm{a}}$ and without variants in the IPF1 gene

\begin{tabular}{lllll}
\hline & $\begin{array}{l}\text { Diabetic mutation } \\
\text { carriers } \\
(n=10)\end{array}$ & $\begin{array}{l}\text { Diabetic subjects } \\
\text { without mutations } \\
(n=15)\end{array}$ & $\begin{array}{l}\text { Non-diabetic } \\
\text { mutation carriers } \\
(n=12)\end{array}$ & $\begin{array}{l}\text { Non-diabetic subjects } \\
\text { without mutations } \\
(n=24)\end{array}$ \\
\hline Age (years) & $61 \pm 5$ & $53 \pm 5$ & $42 \pm 4$ & $39 \pm 3$ \\
BMI (kg/m $\left.{ }^{2}\right)$ & $25.6 \pm 1.2$ & $24.9 \pm 1.0$ & $26.1 \pm 3.2$ & $24.4 \pm 4.4$ \\
Age at onset (years) & $43 \pm 6$ & $46 \pm 6$ & - & - \\
Systolic BP (mmHg) & $136 \pm 7$ & $143 \pm 7$ & $128 \pm 3$ & $123 \pm 4$ \\
Diastolic BP (mmHg) & $77 \pm 3$ & $82 \pm 3$ & $79 \pm 2$ & $78 \pm 2$ \\
HbA $_{1 \mathrm{c}}(\%)$ & $7.2 \pm 0.5$ & $7.1 \pm 0.4$ & - \\
Cholesterol (mmol/l) $_{\text {Triglyceride (mmol/1) }}^{6.5 \pm 0.3 *}$ & $5.3 \pm 0.2 *$ & $5.5 \pm 0.4$ & $5.0 \pm 0.2$ \\
Fasting BG (mmol/l) & $2.1 \pm 0.4$ & $1.5 \pm 0.2$ & $1.8 \pm 0.4$ & $1.3 \pm 0.1$ \\
\hline
\end{tabular}

${ }^{a}$ Including 3 D76N, 6 P239Q and 1 G212R diabetic mutation carriers and 2 D76N, 8 P239Q and 2 G212R non-diabetic mutation carriers. Subjects carrying both MODY4 and MODY3 gene mutations are not included. BP: blood pressure. $* p<0.01$

with MODY. In a Danish study, however, the D76N variant did not show any reduction in transcriptional activation of the insulin promoter when expressed in NIH-3T3 cells [17]. In the present study, the D76N variant was identified in one MODY3 family (S315fsinsA of $H N F-1 \alpha$ gene) and in two families with late-onset diabetes. This emphasizes the need to include also patients with known MODY or other diabetes mutations in the search for novel susceptibility genes for diabetes.

The novel amino acid substitution G212R was detected in only one family with early-onset diabetes. This family fulfilled many features of MODY with an apparent autosomal dominant inheritance and diabetes in at least two subjects with an onset younger than 25 years of age. The variant was, however, also detected in two non-diabetic family members and thus did not co-segregate with diabetes in this family. The $\mathrm{P} 239 \mathrm{Q}$ variant was the most common $I P F 1$ variant in this cohort and was identified in two families with early-onset diabetes, one of which had MODY3 (R272C) and in 3 families with late-onset Type II diabetes except for one control subject without family history of diabetes. This mutation seems to be in a polyproline stretch, which has been associated with lateonset Type II diabetes [19].

In this study, functional analyses indicated that both these novel variants in the IPF1 gene, G212R and P239Q were associated with decreased in vitro activation of human insulin gene transcription compared with the wild-type IPF1. Unlike IPF1 mutations identified previously C18R, D76N, and R197H [9], all of which had deleterious effects on insulin gene transcription through a reduced ability of the proteins to bind to the gene promoter, the G212R and P239Q mutations identified here have normal binding activity. We confirm that these mutations have significant effects on insulin gene transcription through reduced transcriptional activation, a finding supported by our observed effects on activation of the pCAT5xB reporter gene construct, and by analysis of transcriptional activation properties of these mutants through the creation and analyses of Gal4 fusion proteins. Although it has been questioned in other cell lines whether the C-terminus has any transactivation potential $[20,21]$, these in vitro data are supported by the clinical finding of impaired insulin response to OGTT (relative to the glucose concentration) in carriers of both of these variants ( 7 out of 10 had the $P 239 Q$ variant).

The question arises as to whether the IPF1 gene should be considered a MODY gene or whether it increases susceptibility to the more common form of late-onset Type II diabetes. Homozygous mice with targeted disruption of the IPF1 gene selectively lack pancreas and die within a few days of birth, suggesting that the IPF1 gene plays a pivotal part in the development of the pancreas. There were no phenotypic differences, however, between heterozygous mutant and wild-type mice [7, 19]. Furthermore, adult mice with heterozygous disruption of the IPF1 gene developed normally but had impaired glucose tolerance [22], suggesting that IPF1 could be required for maintaining normal glucose tolerance. Thus, variants in the IPF1 gene might predispose certain subjects to late-onset Type II diabetes, particularly if other genetic variants are present [22]. In humans, the IPF1 Pro63fsdelC mutation reported in a family with MODY4 not only results in a truncated protein which lacks part of the homeodomain region required for DNA binding and nuclear localization but also directs expression of a dominant negative isoprotein that inhibits transactivation of the wild-type IPF1 protein [23]. The average age at onset of diabetes in this MODY4 family was 35 years (17-67 years), which is much later than in families with classical MODY. Only one heterozygous mutation carrier developed diabetes before 25 years of age, whereas three heterozygous mutation carriers (22, 23 and 29 years old) did not develop diabetes at the last ascertainment [8].

At present, 5 functional IPF1 variants have been confirmed to predispose to or cause impaired insulin secretion in Type II diabetes: C18R, Q59L, D76N, $\mathrm{R} 197 \mathrm{H}$ and insertion CCG 243. In this study, we con- 

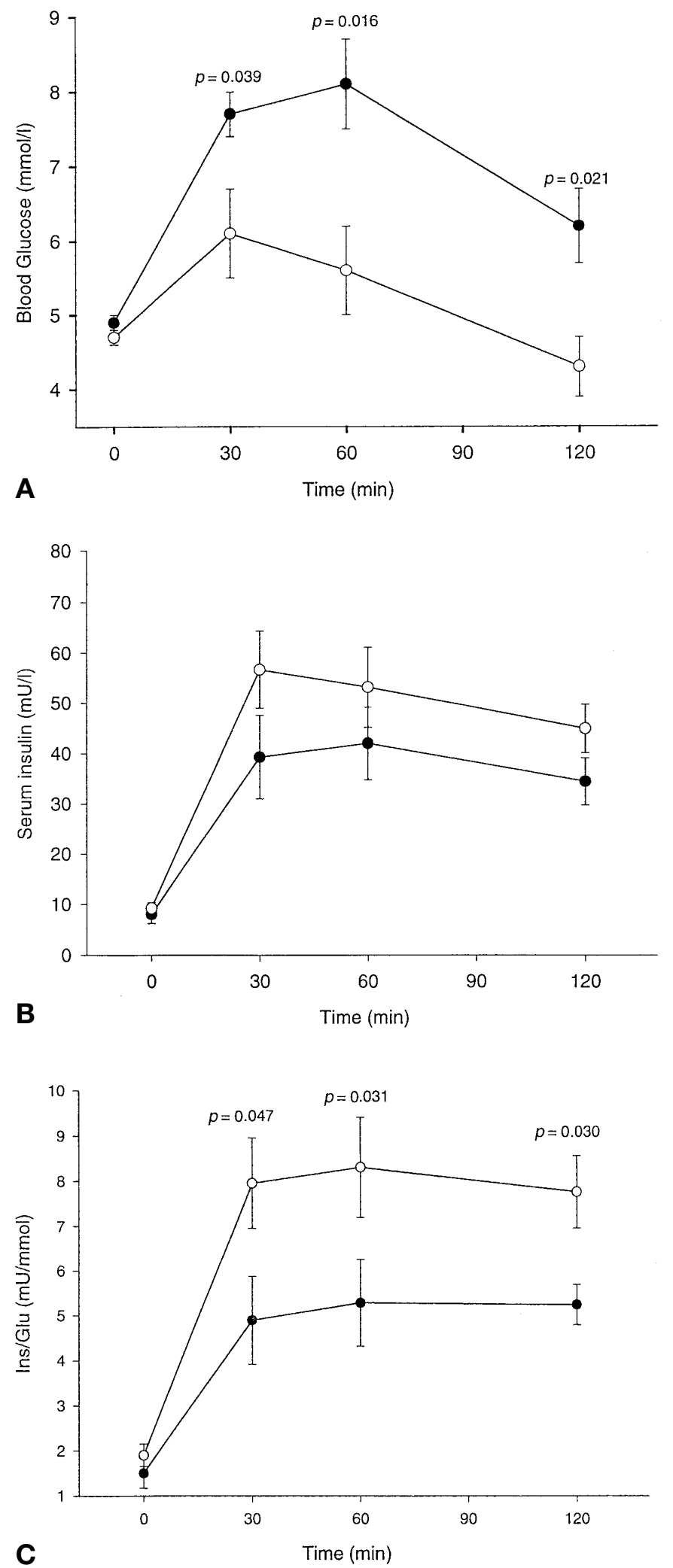

Fig. 6. Blood glucose (A), serum insulin (B) and (C) insulin: glucose ratio during an oral glucose tolerance test in 10 non-diabetic carriers of any variant in the IPF1 gene (black circles) and in 10 non-diabetic non-carriers of these variants (open circles) firmed the D76N mutation and identified two novel functional mutations G212R and P239Q in families with late-onset Type II diabetes and MODY3 (D76N in GS and P239Q in JS family). It is obvious from the pedigrees that the variants do not co-segregate with diabetes in the families. This does not rule out the possibility that they can increase susceptibility to diabetes. It is noteworthy that the non-diabetic carriers of the variants already showed decreased insulin secretion after glucose challenge compared with their non-diabetic relatives without the variants. When expressed in vitro, the mutants $(\mathrm{G} 212 \mathrm{R}$ and $P 239 Q)$ showed normal expression and binding activity to the insulin gene promoter but reduced activation of insulin-gene transcription in response to increased glucose concentrations compared with the wild-type IPF1 protein.

The diabetic mutation carriers also showed higher cholesterol concentrations than the diabetic non-carriers of the mutations. We have no apparent explanation for this finding, but changes in lipid concentrations have also been reported with mutations in another transcription factor, HNF- $4 \alpha$ and ascribed to effects on expression of apolipoproteins [24]. We have no information on whether IPF1 would influence genes involved in cholesterol metabolism.

In conclusion, our data suggest that heterozygous variants in the IPF1 gene are associated with impaired in vitro transcription of the insulin gene at high glucose concentrations and in vivo with impaired insulin response to oral glucose. These variants are not restricted to patients with early-onset diabetes or MODY. Their occurrence in families with MODY3 mutations rather suggest that they act as modifying genes which together with variants in other genes could increase susceptibility to different types of diabetes.

Acknowledgements. We thank the members of the families for their willingness to participate in the studies. This study was supported by grants from the Sigrid Juselius Foundation, the Swedish Medical Research Council, the Finnish Diabetes Research Foundation, the Finnish Medical Society (CF), a JDFWallenberg grant, an EC Grant BMH4-CT95-0662 (LG), the Wellcome Trust and the British Diabetic Association (WMM) and from the Albert Påhlssons Foundation; the Anna Lisa and Sven-Eric Lundgrens Foundation, Medical Faculty of Lund University, the Royal Physiographic Society in Lund, Swedish Society for Medical Research, the University Hospital MAS funds (ML).

\section{References}

1. Hattersley AT (1998) Heterogeneity in Type II diabetes: lessons from maturity-onset diabetes of the young. Diabetes Review International 7: 10-14

2. Horikawa Y, Iwasaki N, Hara M, Furuta H, Hinokio Y, Cockburn BN (1997) Mutation in hepatocyte nuclear factor-1 gene (TCF2) associated with MODY. Nat Genet 17: 384-385 
3. Lehto M, Wipemo C, Ivarsson SA et al. (1999) High frequency of mutations in MODY and mitochondrial genes in Scandinavian patients with familial early-onset diabetes. Diabetologia 42: 1131-1137

4. Weng JP, Lehto M, Forsblom C, Huang X, Li H, Groop LC. (2000) Hepatocyte nuclear factor $-1 \beta$ (MODY5) gene mutations in Scandinavian families with early-onset diabetes or kidney disease or both. Diabetologia 43: 131-132

5. Inoue H, Riggs AC, Tanizawa, Yueda K, Kuwano A, Liu L, Donis-Keller H, Permutt MA (1996) Isolation, characterisation, and chromosomal mapping of the human insulin promoter factor 1 (IPF-1) gene. Diabetes 45: 789-794

6. Ohlsson H, Karlsson K, Edlund T (1993) IPF1, a homeodomain-containing transactivator of insulin gene. EMBO J 12: 4251-4259

7. Jonsson J, Karlsson L, Edlund T, Edlund H (1994) Insulinpromoter-factor 1 is required for pancreas development in mice. Nature 371: 606-609

8. Stoffers DA, Ferrer J, Clarke WL, Habener JF. (1997) Early-onset diabetes mellitus (MODY4) linked to IPF 1. Nat Genet 17: 138-139

9. Macfarlane WM., Frayling TM, Ellard S et al. (1999) Missence mutations in the insulin promoter factor-1 gene predispose to Type II diabetes. J Clin Invest 104: R33-39

10. Hani EH, Stoffers DA, Chevre JC et al. (1999) Defective mutations in the insulin promoter factor-1 (IPF1) gene in late-onset Type II diabetes mellitus. J Clin Invest 104: R41-48

11. Groop L, Forsblom C, Lehtovirta M et al. (1996) Metabolic consequences of a family history of NIDDM (The Botnia Study). Diabetes 45: 1585-1593

12. Macfarlane WM, Chapman RM, Shepherd RM et al. (1999) Engineering a glucose-responsive human insulin secreting cell line from islets of Langerhans isolated from a patient with persistent hyperinsulinaemic hypoglycaemia of infancy. J Biol Chem 274: 34059-34066

13. Macfarlane WM, Read ML, Gilligan M, Bujalska I, Docherty K (1994). Glucose modulates the binding activity of the $\beta$-cell transcription factor IUF1 in a phosphorylationdependent manner. Bioch J 303: 625-631
14. Sadowski I, Ptashne M (1989) A vector for expressing GAL4(1-147) fusions in mammalian cells. Nuc Acids Res 17: 18

15. Macfarlane WM, Shepherd RM, Cosgrove KE, James RFL, Dunne MJ, Docherty K (2000) Glucose modulation of insulin mRNA concentrations is dependent on PDX1, and occurs independently of changes in intracellular $\mathrm{Ca}^{2+}$. Diabetes (In Press).

16. Lu M, Miller CP, Habener JF (1996) Functional regions of the homeodomain protein IDX-1 required for transactivation of the rat somatostatin gene. Endocrinology 137: 2959-2967

17. Hansen L, Urioste S, Petersen HV et al. (2000) Missense mutations in the human insulin promoter factor-1 gene and their relation to maturity-onset diabetes of the young and late-onset Type II diabetes mellitus in Caucasians. JCEM 85: 1323-1326

18. Stoffers DA, Ferrer J, Clarke WL, Habener JF (1997) Early-onset type II diabetes mellitus (MODY4) linked to IPF1. Nat Genet 17: 138-139

19. Offield MF, Jetton TL, Labosky PA et al. (1996) PDX-1 is required for pancreatic outgrowth and differentiation of the rostral duodenum. Development 122: 983-995

20. Peers B, Leonard J, Sharma S, Teitelman G, Montminy MR (1994) Insulin expression in pancreatic islet cells relies on cooperative interactions between the helix loop helix factor E47 and the homeobox factor STF-1. Mol Endocrinol 8: 1798-1806

21. Peshavaria M, Henderson E, Sharma A, Wright CVE, Stein R (1997) Functional characterization of the transactivation properties of the PDX-1 homeodomain protein. Mol Cell Biol 17: 3987-3996

22. Dutta S, Bonner-Weir S, Montminy M (1998) Regulatory factor linked to late-onset diabetes? Nature 392: 560

23. Stoffers DA, Stanojevic V, Habener JF (1998) Insulin promoter factor-1 gene mutation linked to early-onset Type II diabetes mellitus directs expression of a dominant negative isoprotein. J Clin Invest 102: 232-241

24. Lehto M, Bitzén P-O, Isomaa B et al. (1999) Mutations in the HNF4 $\alpha$ gene affect insulin secretion and triglycerine metabolism. Diabetes 48: 423-425 